\title{
El castigo
}

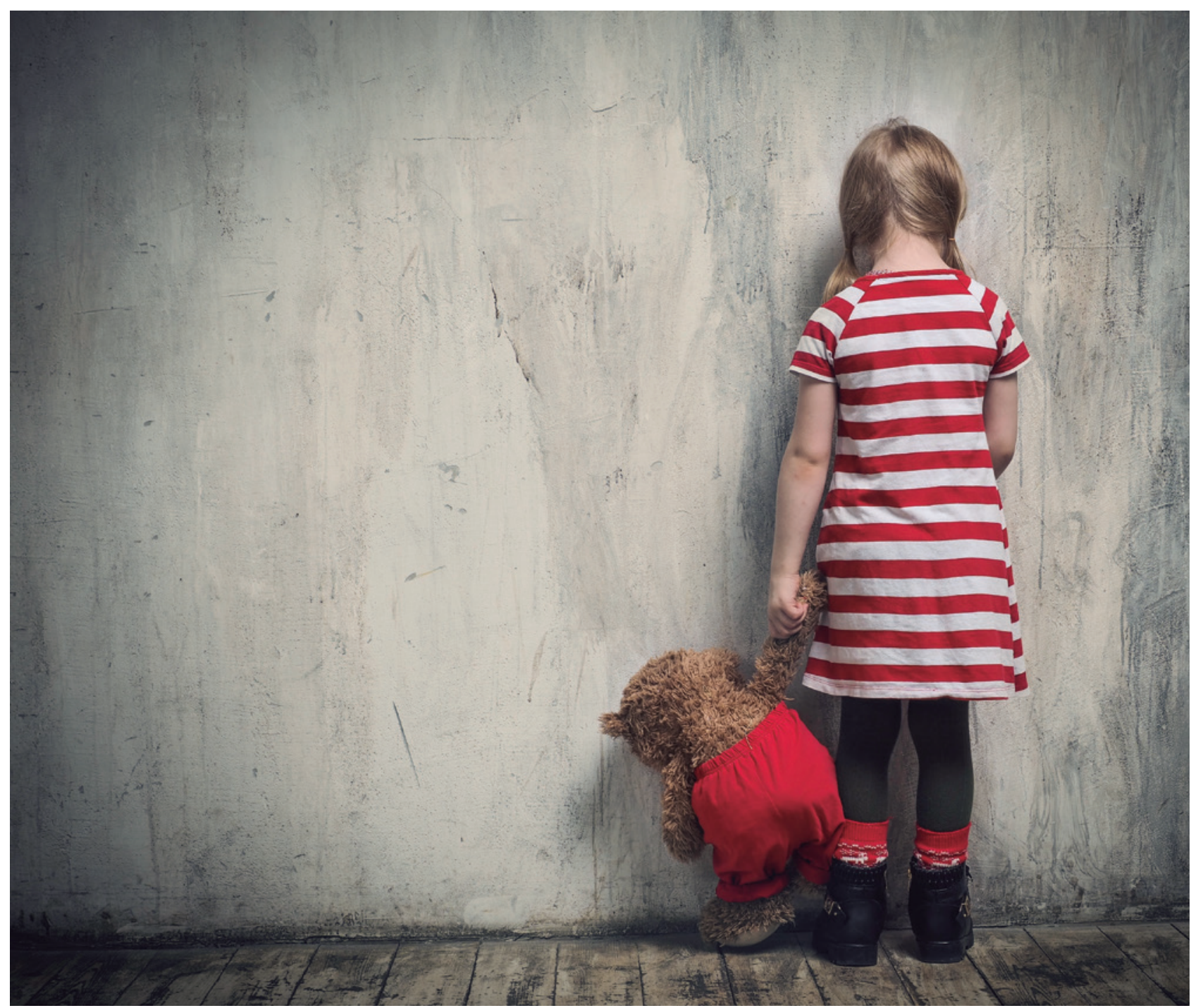

Es muy probable que usted haya escuchado o leído en más de una ocasión frases del tipo: "No creo en el castigo. El castigo no funciona. El castigo es opresivo o una forma de maltrato. El castigo daña la autoestima. El castigo traumatiza. Se puede y se

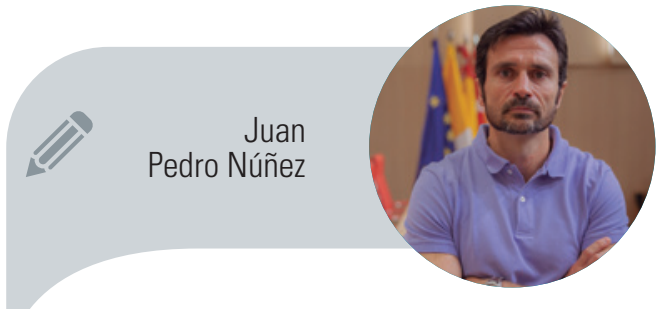
debe educar solo con refuerzos. Y todo esto está además demostrado por la investigación". Pues bien, todas estas afirmaciones son absurdas, medias verdades o incluso falsas. 


\section{Aclarando términos}

Empezaremos por definir qué entendemos por castigo y así sabremos de qué estamos hablando. "El castigo es el proceso por el que la frecuencia de un comportamiento disminuye o desaparece debido a las consecuencias fundamentalmente negativas que acarrea". Es importante señalar que consecuencias fundamentalmente negativas incluye la pérdida de beneficios y que estas han de tener un impacto mayor que los posibles beneficios asociados al comportamiento en cuestión. Y dicho impacto depende entre otros factores de:

1. La diferencia de intensidad o magnitud entre el daño o la pérdida y el beneficio.

2. De la regularidad con la que las consecuencias siguen a la conducta.

3. Del intervalo de tiempo que transcurre entre la conducta y sus consecuencias.

4. De las capacidades, gustos y preferencias del sujeto en cuestión.

En definitiva, cualquier cosa que usted haya dejado de hacer o tienda a hacer menos porque fundamentalmente no le merece la pena o no le trae nada bueno es porque dicho comportamiento ha sido castigado (por ejemplo, meter los dedos en un enchufe). De lo que estamos hablando, por tanto, es de un principio o ley universal que rige el comportamiento de cualquier organismo vivo o sistema artificial funcionalmente válido. Cualquier organismo que no se rigiera por dicho principio, es decir, que repitiera comportamientos cuyas consecuencias fueran fundamentalmente dañinas, estaría destinado a la autodestrucción, a la no supervivencia de la especie. Así pues, decir que no se cree en el castigo o que el castigo no funciona es como decir que no se cree en la ley de la gravedad y que por tanto al tirar una piedra al aire esta no caerá.

Es más, en sistemas u organismos dotados de una mínima inteligencia y capacidad de procesamiento de información, y en el caso del ser humano dichas capacidades están muy desarrolladas, basta la previsión del daño, sin que este haya ocurrido nunca, para que la conducta cambie.

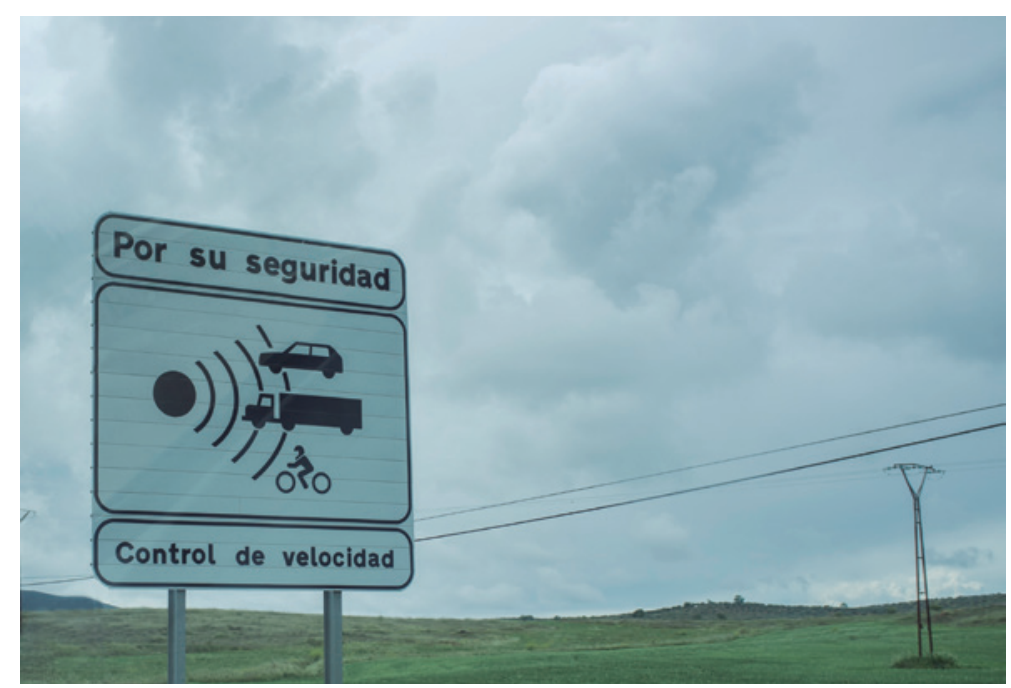

La amenaza de una buena multa junto con un coche de la guardia civil hace que la mayoría, por no decir la totalidad de los conductores, ajustemos nuestra velocidad al límite indicado.

El castigo es un fenómeno natural directamente asociado al sentimiento de miedo y a las conductas o respuestas de evitación. El miedo es un sentimiento desagradable de experimentar, pero es nuestro amigo, es uno de los mecanismos más básicos y fundamentales de nuestro cerebro para advertirnos del daño y del peligro que corremos ${ }^{1}$. Sin miedo iríamos de cabeza hacia las fuentes de nuestro sufrimiento y nuestra destrucción. Gracias al miedo, evitamos a toda costa repetir aquellos comportamientos que nos han traído grave daño, es decir, que han sido eficazmente castigados. Las respuestas de evitación son, por tanto, la cara visible del castigo ya que nos protegen del posible daño o pérdida que supondría realizar determinado comportamiento. Dada su función protectora suelen ser muy poderosas (intensas y de rápida ejecución) y como una vez puestas en marcha eliminan de golpe la desagradable sensación de miedo, son muy estables y tienden a perpetuarse. De ahí que sean tan difíciles de erradicar, como ocurre con las fobias -incluso cuando el miedo al estímulo fóbico es irracional (no conlleva daño alguno) pero, como gracias a la evitación el pánico se desvanece, la persona tiende a repetir su conducta evasiva sin enfrentarse nunca a la realidad-.

1 Lo cual no quiere decir que sea perfecto o infalible, como no lo es nada en la naturaleza. 


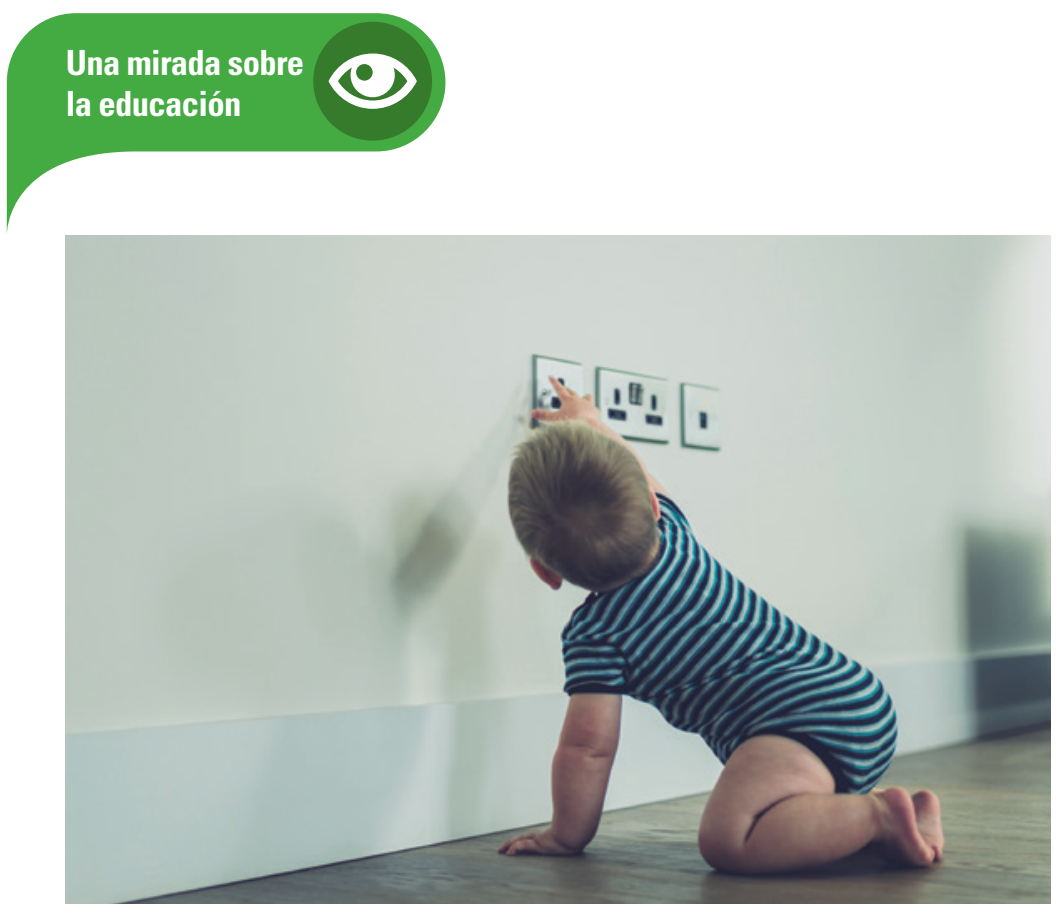

Como vemos, nuestro cerebro está especialmente diseñado para adaptarse a las situaciones nocivas que inevitablemente tengamos que afrontar y a las consecuencias negativas generadas por nuestra actividad. Pone en marcha la reacción emocional de miedo a la mínima señal de alarma y establece poderosos sistemas de respuesta para evitar y eludir las consecuencias perjudiciales de determinados comportamientos o situaciones. Por ello es una auténtica barbaridad afirmar que por sí mismo el castigo daña la autoestima o traumatiza a la persona. De ser así no solo todos los seres humanos estaríamos traumatizados "por naturaleza" y con una autoestima nefasta, sino que sería lo mismo que afirmar que nuestro cerebro - el sistema más complejo y sofisticado fruto de la evolución- ha desarrollado mecanismos absurdos y perversos para afrontar las consecuencias negativas de sus acciones.

\section{Mito y sociedad}

El verdadero peligro está en confundir tener miedo con estar traumatizado o en confundir el castigo con la opresión o el maltrato, pero desgraciadamente como sociedad ya hemos llegado a ese punto de confusión y alteración de la realidad. Si la tendencia se mantiene no sería descabellado imaginar que un padre pudiera ser denunciado por abuso si baña a su hija en contra de su voluntad. Algo que ocurre a diario en todos los hogares porque los niños nunca quieren bañarse cuando llega el momento, o juegan con reclamar a papá o mamá a capricho con independencia del reparto de tareas u ocupaciones que en un momento dado pudieran estar desarrollando sus progenitores.

Por supuesto estamos en nuestro derecho como individuos y como sociedad de no querer utilizar el castigo como herramienta educativa. Siempre podemos optar porque sea la realidad la que enseñe a nuestros hijos las consecuencias de meter los dedos en un enchufe o de cruzar la calle con el semáforo en rojo. La diferencia fundamental estriba, y parece que se nos ha olvidado, en que cuando somos nosotros los que castigamos manejamos el control de daños, mientras que si ha de ser la vida la que enseñe sus cartas las consecuencias pudieran ser terribles e irremediables. El castigo se ha estigmatizado asociándolo al autoritarismo, la opresión y el maltrato. A ello han ayudado sin duda aspectos obvios de nuestra historia tanto política como educativa, pero no nos engañemos, no son esas las únicas razones. Castigar es desagradable y conlleva un gran esfuerzo, pues nos enfrenta al malestar y a la reacción en contra del otro y nos obliga a mantenernos firmes en nuestra posición. Solo las personas sádicas disfrutan con el castigo y, gracias a Dios, no son muchas estadísticamente hablando. Dicha tensión es tan desagradable que, de hecho, tendemos a eludirla incluso entre adultos. Son muchas las veces que preferimos ignorar una ofensa que castigar dicha acción. Lógicamente, castigar a nuestros hijos es mucho más duro porque los queremos y no nos gusta verlos sufrir, son niños y es muy fácil excusar su comportamiento, y en cambio es muy costoso llegar a casa después de una dura jornada de trabajo y tener que poner límites y ejercer la autoridad. Además, como el castigo está mal visto nos sentimos malos padres y nos genera inseguridad no saber qué es lo correcto y cómo actuar, sin contar que vende y nos gusta mucho más la imagen de ser padres dialogantes. Lo que pasa es que la fantasía del "diálogo para todo" no es más que eso, una fantasía. Si nuestros hijos, como nosotros cuando fuimos niños y adolescentes, tienen que ser educados es porque ignoran los aspectos fundamentales de la vida, sus capacidades cognitivas - como el razonamien- 
to- están a medio desarrollar, así como las volitivas y emocionales. Básicamente son una montaña de deseos e impulsos y, contra eso, muchas veces no hay diálogo posible. Ocasionalmente puede parecernos que ganamos la batalla a la sinrazón, pero es una victoria pírrica porque las más de las veces solo hemos conseguido postergarla para otra ocasión o dejarla en manos de otros educadores, o hemos hecho concesiones de las que, más tarde o más temprano, acabaremos arrepintiéndonos, sin contar las trampas o trucos de escasa y corta duración que suponen la distracción o las mentirijillas que usamos como grandes alardes de nuestra inteligencia adulta. La fantasía de los padres dialogantes es la arriesgada realidad de los padres permisivos.

Paradójicamente alabamos y consideramos un elemento propio de la madurez el autocontrol y la autodisciplina que nos permiten no sucumbir a nuestros primeros deseos e impulsos y así poder alcanzar metas y objetivos a largo plazo. Pero se nos olvida que dichas capacidades hay que educarlas, que como todo lo que es complejo exigen mucho entrenamiento y cuanto antes se empiece, más probabilidades hay de desarrollarlas adecuadamente. $Y$ el único camino para favorecer en un niño el autocontrol y la autodisciplina es que un adulto ponga límite y discipline sus impulsos y deseos, lo cual irremediablemente le generará sufrimiento en forma de frustración. Es entonces cuando surge el peligroso mantra de "pobrecito, no le hagas eso, total es solo un niño" que fácilmente convertirá a nuestros hijos en niños malcriados, esclavos de sus propias pataletas, niños tiranos y quien sabe si adultos insoportables, emocionalmente ansiosos, obsesivos o inestables y eternamente insatisfechos porque el mundo no se pone a sus pies y sus deseos no siempre se cumplen. Si el desastre no alcanza cotas mayores es porque la mayoría de las veces nuestros hijos se educan "a pesar de" y no "gracias a" nuestras acciones como padres, pues también educan la vida, el colegio, los amigos.... pero eso no nos exime de nuestra responsabilidad y el

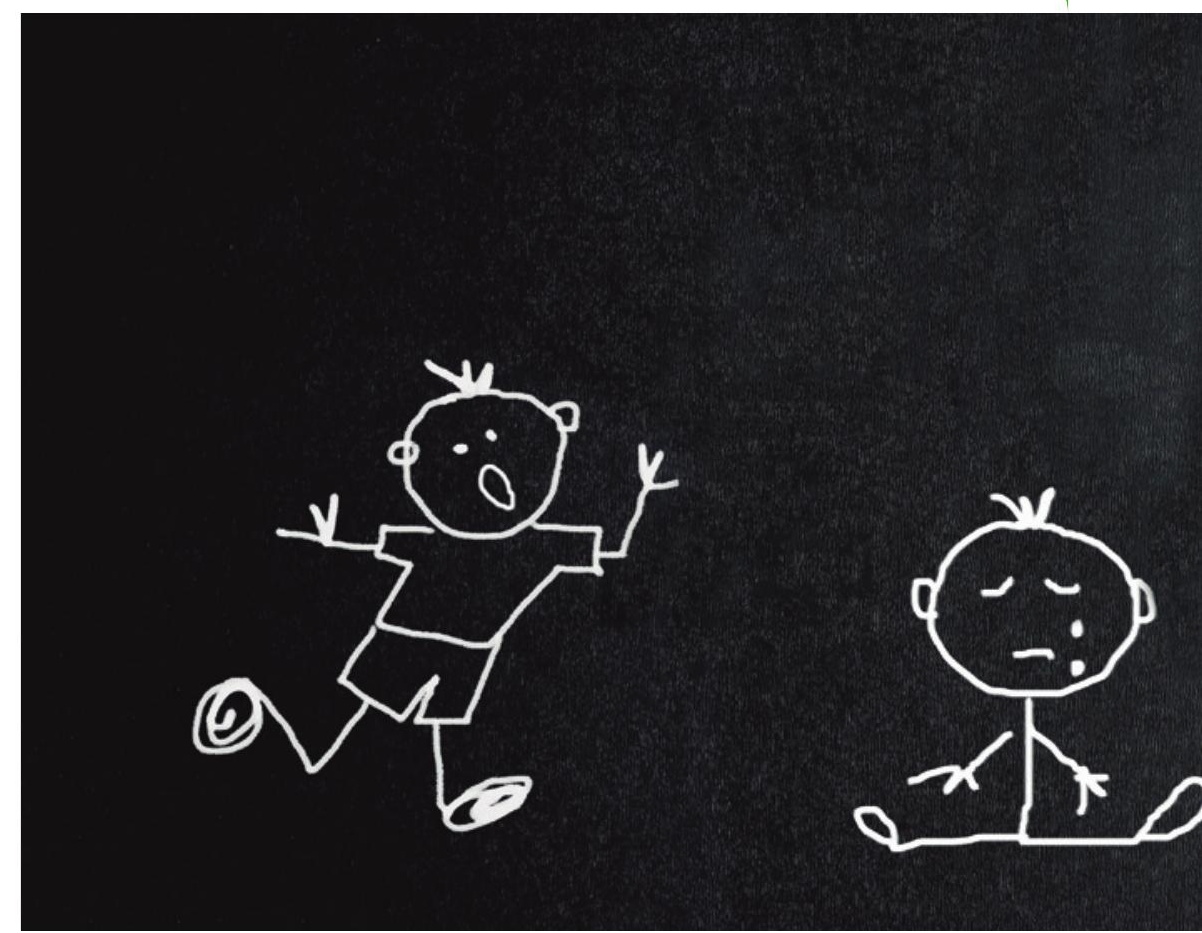

El autocontrol y la autodisciplina hay que educarlas, y el único camino para favorecerlas en un niño es que un adulto ponga límite y discipline sus impulsos y deseos, lo cual irremediablemente le generará sufrimiento en forma de frustración

mito del castigo como dañino no nos ayuda en nuestra importante y difícil labor.

Tal vez no tenga sentido hablar de desastre, pero sí de ciertos indicadores preocupantes. Y aunque España no es el único país de Europa afectado por este fenómeno, sí es el único en el que el cambio ha sido radical. Durante la transición pasamos en un corto espacio de tiempo de un sistema educativo basado casi exclusivamente en cualquier forma de castigo (muchas veces arbitrario, mal aplicado y desproporcionado) a una educación en la que castigar estaba mal visto, pues se asociaba al autoritarismo que queríamos dejar atrás. Dicha tendencia ha Ilegado hasta nuestros días hasta el punto de que casi cualquier forma de castigo roza el delito. Ahora bien, incluso asumiendo que, por supuesto, son muchas más las variables que habría que considerar, tal vez merezca la pena reflexionar hasta qué 


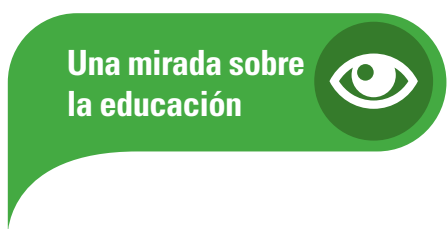

\section{Ilustración 1. Efectos de la amenaza repetida}

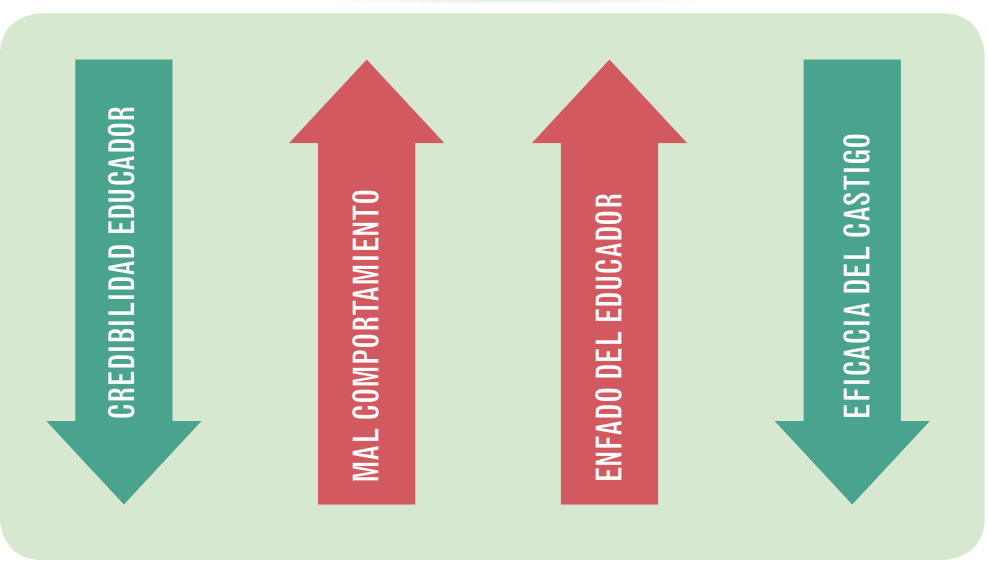

punto este giro en la educación está relacionado con el preocupante incremento que han experimentado las agresiones filoparentales y de alumnos a profesores, el burnout entre el profesorado, las cesiones de tutela por parte de los padres a la administración, el número de diagnósticos psiquiátricos en población infantojuvenil... Al menos no parece que la drástica disminución del castigo como herramienta educativa haya traído mayores cotas de salud, felicidad y seguridad entre padres y profesores, los principales adultos responsables de la educación de los menores, ni tampoco a estos últimos. Y no menos preocupante es la ciega, hipócrita y contradictoria actitud que como sociedad somos capaces de mantener, porque la misma sociedad que desprecia el castigo sale a la calle en masa pidiendo un castigo ejemplar al grito de "no es no" para los culpables de una violación en grupo, o aplaudimos que vayan agentes de policía uniformados a los colegios para "meter miedo" a los niños sobre los peligros de internet y las redes sociales (porque no nos engañemos, idéntica información podríamos dársela los padres o los profesores, incluso los mismos agentes sin uniforme, pero valoramos dicha puesta en escena porque sabemos que aumenta la sensación de gravedad y, por tanto, aumenta la probabilidad de que se reduzcan o eliminen ciertas prácticas).

\section{¿Refuerzo para todo?}

La educación a base exclusivamente de refuerzos no es ninguna panacea. En primer lugar, porque supone un claro alejamiento de la realidad ya que muchos de

nuestros actos tienen consecuencias desagradables y no siempre hay un premio inmediato y apetecible por ajustarnos a las normas sociales o las reglas de la naturaleza. En segundo lugar, si hemos de dar un premio a un niño cada vez que queramos que haga " $X$ " o para que no haga o deje de hacer "Y", automáticamente el control pasa a tenerlo el educando y no el educador ya que cuando el refuerzo no sea suficiente, o simplemente el niño quiera más u otro premio distinto, solo tiene que actuar en consecuencia para que el adulto se someta y satisfaga sus deseos y demandas. Obviamente, como vemos, no hay ningún misterio en el aumento de "niños tiranos" o con el "síndrome del emperador". En tercer lugar, y es algo que casi nadie explica, es que los fenómenos de habituación y saciación afectan mucho más rápido a los estímulos reforzadores que a los estímulos aversivos, por lo que su efectividad disminuye en poco tiempo y puede ser una auténtica locura buscar nuevas fuentes de estimulación para lograr que nuestros hijos sigan determinadas normas de conducta. El problema, como siempre, no es solo para los padres, dicha dinámica también conlleva una perversa espiral para los niños acostumbrados a actuar a base de estimulación positiva en una escalada imposible, por lo que las inevitables sensaciones de desmotivación y aburrimiento se vuelven insoportables y dan paso a la búsqueda obsesiva de sensaciones positivas, donde no sería tan raro que apareciesen conductas de riesgo, adicciones, ansiedad, etc.

\section{El buen castigo}

El uso correcto del castigo como herramienta educativa no es sencillo. Como ya hemos señalado, tiene un coste importante ya que no es fácil ni cómoda su aplicación. Al castigar nos convertimos automáticamente en un aguafiestas, en el malo de la película, y además debemos dedicar energía, tiempo y esfuerzo en mantenernos en tan incómoda situación el tiempo necesario para que el castigo sea eficaz. Recordemos también que la eficacia del castigo depende de que las consecuencias 
de determinado comportamiento sean fundamentalmente negativas. Es decir, que el malestar y el sufrimiento que generen deben ser superiores al beneficio o el placer que dicho comportamiento reporte, por lo que hay que tener claro dicho balance. También es muy importante que las consecuencias negativas sean constantes y habituales, por eso no podemos ni debemos mirar para otro lado o hacernos los despistados. Si estas solo sobrevienen de vez en cuando, lo normal es que aparezcan comportamientos tentativos y sea mucho más difícil que la conducta desaparezca. Por eso somos muchos los conductores que seguimos conduciendo por encima de los límites de velocidad permitidos, aunque alguna que otra vez hayamos sido multados.

Además, lo ideal es castigar inmediatamente y a la primera, en cuanto el comportamiento indeseado aparece. No hay error más grave que avisar o amenazar insistentemente con un castigo para aplicarlo tarde o no aplicarlo. Solemos actuar así porque en el fondo no queremos castigar, no nos apetece, esperamos que con nuestra amenaza baste. Lo cual es una grandísima estupidez porque básicamente con cada aviso o amenaza no cumplida el mensaje que estamos enviando es que nuestra palabra no vale, que es una gran farsa. Pretender luego que el otro reaccione en el momento oportuno, precisamente, cuando más agotada está nuestra credibilidad y simplemente porque ya estamos hartos, es ridículo. Lo peor es que llevados por nuestro hastío actuamos cabreados ya que, en nuestra pueril visión del asunto, cada aviso ha sido una oportunidad que hemos dado, un generoso ejercicio de paciencia que no se nos ha valorado y es entonces cuando nos sentimos más justificados para actuar y usamos un tono que dista mucho de ser el tono neutro con el que deberíamos castigar. Solemos además cargar las tintas contra la persona ("me tienes harto", "eres insoportable...", lo que dicho sea de paso es lo que verdaderamente puede dañar la autoestima) en vez de limitarnos solo a castigar el comportamiento. Y con ello facilitamos que el niño entienda toda esa parafernalia como una cuestión puramente
Ilustración 2. Hablando claro

$\rightarrow$ El castigo es un proceso natural de aprendizaje que previene y evita comportamientos de consecuencias indeseables 0 dañinas para la persona.

$\Rightarrow$ El castigo bien aplicado es una herramienta educativa necesaria y muy eficaz.

$\rightarrow$ El castigo se ha estigmatizado socialmente.

$\rightarrow$ El castigo bien aplicado ni traumatiza ni daña la autoestima.

$\rightarrow$ Castigar nos supone un gran esfuerzo y mucha incomodidad y por eso preferimos evitarlo.

$\rightarrow$ Pretender educar solo con refuerzos tiene grandes limitaciones y da poder al educando sobre el educador.

$\rightarrow$ Tampoco es viable educar solo a base de castigos.

$\rightarrow$ Una forma perjudicial de castigo es usar nuestro enfado 0 nuestro dolor para culpabilizar al menor.

arbitraria y caprichosa, simplemente que papá o mamá hoy tenían un mal día y se han hartado (y no lo verdaderamente importante y es que su comportamiento era inadecuado). Así pues, la próxima vez será solo cuestión de identificar el punto crítico de paciencia de nuestros padres para seguir actuando según nos plazca. Lo peor de todo es cuando directamente aplicamos como castigo nuestro enfado o malestar para culpabilizar al menor. Dicha manipulación afectiva no puede ser más contraproducente e inadecuada educativamente hablando. Y no es que no podamos enfadarnos, pero nunca usarlo instrumentalmente para alcanzar objetivos educativos o como "venganza". Nuestros hijos tienen que tener muy claro que nuestro afecto por ellos está garantizado. Lo ideal es aplicar los castigos con neutralidad emocional, lo que es más fácil si lo hacemos desde el primer momento sin permitir que la situación nos desborde. Y al separar el verdadero castigo de nuestro posible y puntual enfado facilitamos que el niño entienda que se trata de dos aspectos distintos de la realidad, especialmente si se lo explicamos y sobre todo si actuamos en consecuencia.

Otro error que solemos cometer es que pretendemos castigar sin que "duela", pero que funcione, por lo que aplicamos castigos de baja intensidad. Lógicamente, como no tienen el efecto deseado vamos aumentando paulatinamente la magnitud 


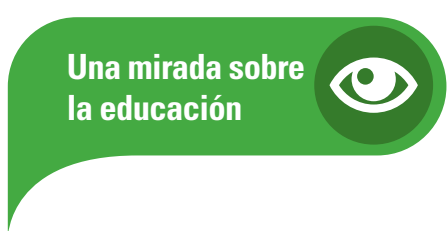

\section{Ilustración 3. El castigo como camino para el autocontrol}

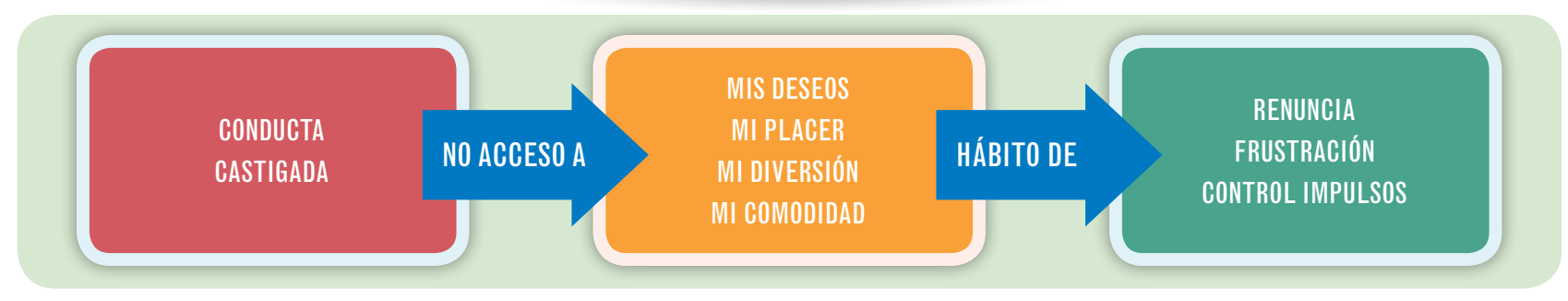

del castigo para acabar descubriendo que sigue sin funcionar "hagamos lo que hagamos". Imaginemos ahora que por superar el límite de velocidad nos pusieran una multa de $1 €$ y que la segunda vez la multa fuera de $2 €$ y así sucesivamente hasta que mil veces después de haber infringido el límite de velocidad pagáramos un multazo de 1.000€. Supongo que será fácil de entender que si la primera multa hubiese sido directamente de mil euros el panorama sería muy diferente ya que, por un lado, es mucho más difícil erradicar un comportamiento que está muy arraigado $y$, por otro, el incremento paulatino del castigo favorece la habituación y relativiza el impacto del daño ("es solo $1 €$ más que la última vez").

Y, por último, no debemos olvidar que lo que nos resulta desagradable o doloroso es en gran medida una variable individual, así que lo que puede ser eficaz para un niño (quedarse sin recreo) puede no serlo para otro.

\section{Un apunte final}

En cuanto a la investigación sobre el castigo tenemos que diferenciar la investigación puramente experimental y la basada en cuestionarios. La primera es mucho más fiable y rigurosa y es a la que debemos los datos que nos hablan de la eficacia del castigo y de las variables que la modulan. Con el paso del tiempo ese tipo de investigación ha ido cayendo en desuso por las trabas que han ido implementando los comités éticos de los distintos centros de investigación, encargados de minimizar el malestar a los participantes en un estudio. De ahí que la investigación basada en cuestionarios y autoinformes sea la más frecuente en la actualidad, pero una vez que hemos comprendido lo fácil que es aplicar mal el castigo, no es de extrañar que muchos de sus resultados apunten a que este no es eficaz o trae consecuencias indeseables. Pero no dejan de ser indicadores más que cuestionables, ya que no diferencian entre el castigo bien o mal aplicado, ni se controlan variables como la intensidad o calidad del estímulo aversivo utilizado, el beneficio asociado a la conducta a castigar, el momento o la regularidad en su aplicación u otras características de la muestra, etc.

Educar bien no es tarea fácil y exige el uso adecuado de todas las herramientas que tengamos a mano. Tan absurdo y limitador es prescindir del refuerzo como hacerlo del castigo, si bien con el primero nos sentimos muy cómodos y con el segundo no. Pero ni nuestra comodidad ni una mal entendida protección de los menores deberían cegarnos tanto como parece está ocurriendo en este caso, porque a fin de cuentas los que salen perjudicados son los niños y adolescentes que podrían desarrollar actitudes y comportamientos que a la larga no les traerían nada bueno $•$

\section{HEMOS HABLADO DE}

\section{Castigo; refuerzo; educación; aprendizaje; problemas.}

Este artículo fue solicitado por PADRES Y MAESTROS en marzo de 2020, revisado y aceptado en junio de 2020. 